\title{
Staphylococcus aureus Resistance Patterns in Wisconsin:
}

\section{Surveillance of Wisconsin Organisms for Trends in Antimicrobial Resistance and Epidemiology (SWOTARE) Program Report}

\author{
Rebecca H. Schulte, BS and Erik Munson, PhD
}

\begin{abstract}
Objective: Surveillance of antimicrobial resistance patterns on a local level can reveal paradigms not obvious on a regional or national scale. Data collection from this perspective may potentially impact local prescribing patterns and empiric treatment guidelines. The objective of this study was to establish a baseline Staphylococcus aureus antibiogram for the state of Wisconsin and to elucidate potential geographic and demographic factors associated with antimicrobial resistance.
\end{abstract}

Design: Multi-center laboratory surveillance, with testing at a single site utilizing standardized media and susceptibility testing protocols.

Methods: 309 isolates of clinically-significant S. aureus were collected from hospital microbiology laboratories across Wisconsin in 2018, with distribution across seven geographic regions. Each isolate was tested using reference broth microdilution methods against a panel of 15 antimicrobial agents. Percentage susceptibility data, as well as median and 90 th percentile minimum inhibitory concentration (MIC) values, were computed for each antimicrobial agent as a function of geographic region or demographic category.

Results: Increased resistance to penicillin ( $\geq 86.0 \%$ of isolates), erythromycin ( $\geq 56.8 \%$ ), cefoxitin ( $\geq$ $45.5 \%)$, levofloxacin $(\geq 25.0 \%)$, and clindamycin $(\geq 20.5 \%)$ was observed in the Southcentral, Lake Winnebago, and Southeast regions of Wisconsin. In addition, isolates phenotypically classified as methicillin-resistant $S$. aureus (MRSA) were found to have increased rates of resistance to clindamycin, erythromycin, and levofloxacin as compared to $S$. aureus isolates susceptible to cefoxitin. S. aureus isolates demonstrated nearly $100 \%$ in vitro susceptibility to ceftaroline, dalbavancin, and telavancin. Statewide S. aureus isolates exhibited a vancomycin $\mathrm{MIC}_{90}$ of I $\mu \mathrm{g} / \mathrm{mL}$. S. aureus isolates from patients aged 20-39 years were more likely to demonstrate cefoxitin resistance when compared to other age groups $(P \leq 0.03)$, while isolates from patients $\geq 80$ years were more likely to exhibit resistance to levofloxacin and clindamycin $(P \leq 0.046)$.

Conclusions: Several antimicrobial agents continue to demonstrate in vitro efficacy against clinical isolates of S. aureus (including MRSA) throughout Wisconsin, including three agents with recentlypublished susceptibility testing guidelines. However, continued surveillance efforts may be necessary in the Lake Winnebago, Southeast, and Southcentral regions to further assess higher rates of resistance to a number of antimicrobial agents.

Keywords: Staphylococcus aureus; Antimicrobial resistance; Surveillance

Corresponding Author: Erik Munson, PhD, Department of Clinical Laboratory Science, Marquette University, PO Box I88I, Milwaukee, Wisconsin 5320I-I88 I

Telephone: (4I4) 288-5848, Fax: (4I4) 288-7948, Email: erik.munson@marquette.edu
Received: May 2, 2019

Revised: July 18, 2019

Accepted:August 7, 2019

Financial Support: The research received support from the Wisconsin Department of Health Services, Division of Public Health (ELC Project K2: HAI Coordinated Prevention and Stewardship). 
A ccording to the World Health Organization, significant increases in antimicrobial resistance have occurred in recent years. ${ }^{1}$ In addition to agents of healthcareassociated infection such as extended-spectrum $\beta$-lactamaseproducing Enterobacterales, carbapenemase-producing organisms, and vancomycin-resistant enterococci, ${ }^{2-4}$ emerging agents such as Candida auris ${ }^{5}$ and antibiotic-resistant Neisseria gonorrhoeae ${ }^{6}$ are impacting clinical management of patients and economics of healthcare. ${ }^{7}$ This has resulted in a need for novel antimicrobial agents and new means of treatment for disease states involving these resistant strains. ${ }^{8}$ However, antimicrobial research and development efforts may not come to fruition due to cost considerations or discovery of unexpected toxicity profiles. As a result, development efforts have largely turned to antimicrobial compounds already in use, with the possibility of using them in new combinations (often paired with $\beta$-lactamase inhibitor compounds) to enhance their efficacy. Due to the paucity of novel antimicrobial agents, antimicrobial resistance surveillance can be a means of assessing agents that are currently utilized. ${ }^{9}$ It is important to study these strains of increasingly-resistant bacteria due to potentially novel resistance mechanisms and the potential of developing resistance to alternative therapeutic options. ${ }^{10}$

Staphylococcus aureus is a common human pathogen, with increased antimicrobial resistance complicating therapeutic measures in recent years. In 2014, portions of Southeast Asia, the Western Pacific, and other regions of the world reported greater than $80 \%$ of $S$. aureus infections having a methicillinresistant $S$. aureus (MRSA) phenotype. ${ }^{11}$ In the United States, MRSA was deemed a serious antibiotic resistance threat by the Centers for Disease Control and Prevention in a 2013 report. ${ }^{12}$ Studies have demonstrated that MRSA isolation rates have declined in recent years, yet additional adjunctive surveillance and prevention may be necessary to further decrease the spread of this pathogen. Between 2005-2008, Diekema, et $\mathrm{al}^{13}$ documented international MRSA rates of $44.2 \%$. By 2016 , this rate declined to $39.0 \%$. A study by Sader, et al ${ }^{14}$ reported a shift in MRSA rates from $50.0 \%$ to 42.2\% between 2010 and 2016 in United States hospitals. Landrum, et a ${ }^{15}$ reported decreased trending between 2005 and 2010 for community-onset MRSA bacteremia, hospitalonset MRSA bacteremia, and community-onset skin and soft tissue infection due to MRSA among United States military personnel. By monitoring antibiotic resistance on a local level, healthcare professionals can make informed decisions regarding antimicrobial therapy and infection prevention. ${ }^{16-18}$

In 2014, the Wisconsin Clinical Laboratory Network (WCLN) undertook an effort to monitor statewide antimicrobial resistance patterns. ${ }^{19}$ This means of monitoring involved a compilation of antibiograms submitted on a voluntary basis. Two years later, ${ }^{16,17}$ the Surveillance of Wisconsin Organisms

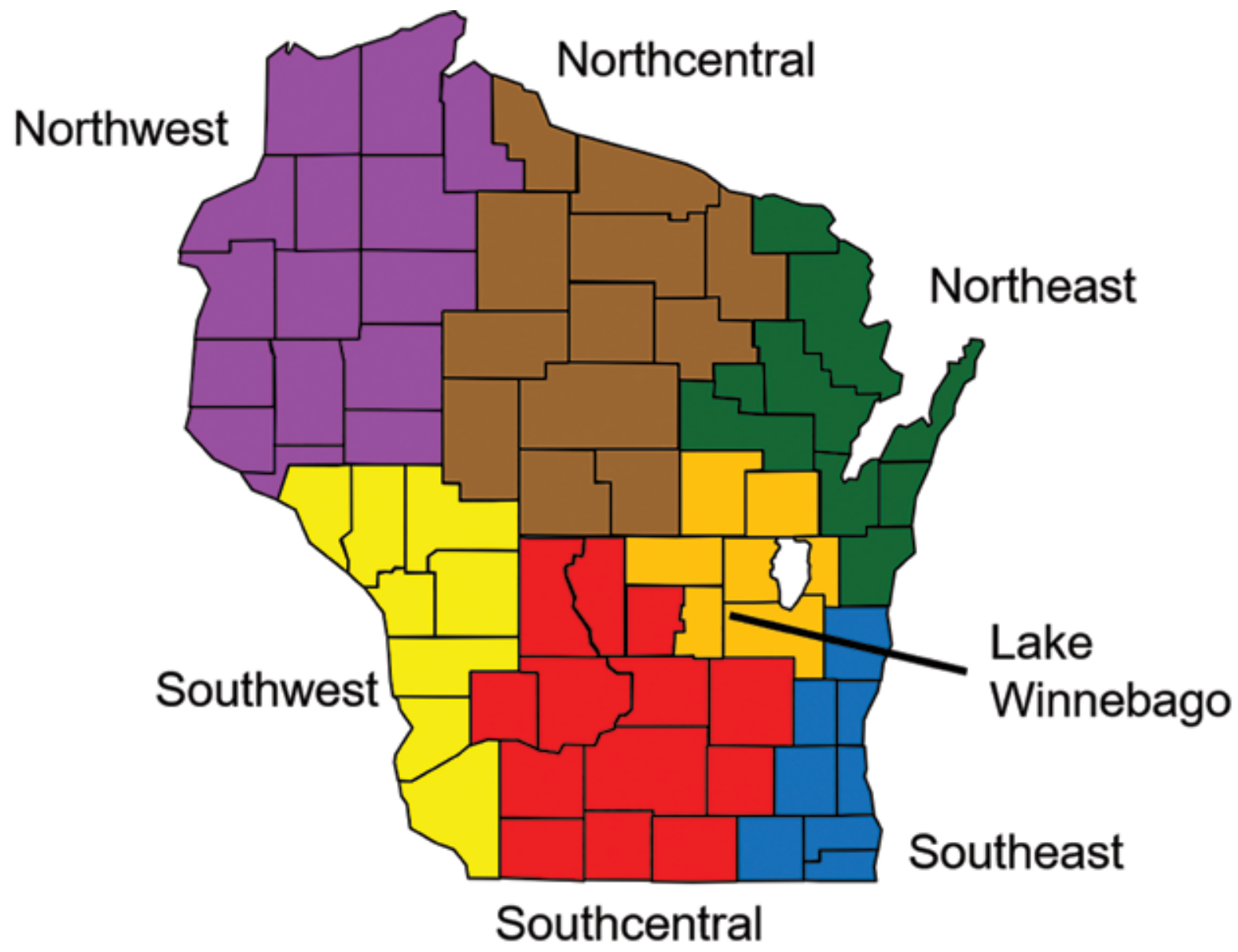

Figure 1. Distribution of seven Wisconsin geographic regions defined by the SWOTARE program, 2018. 


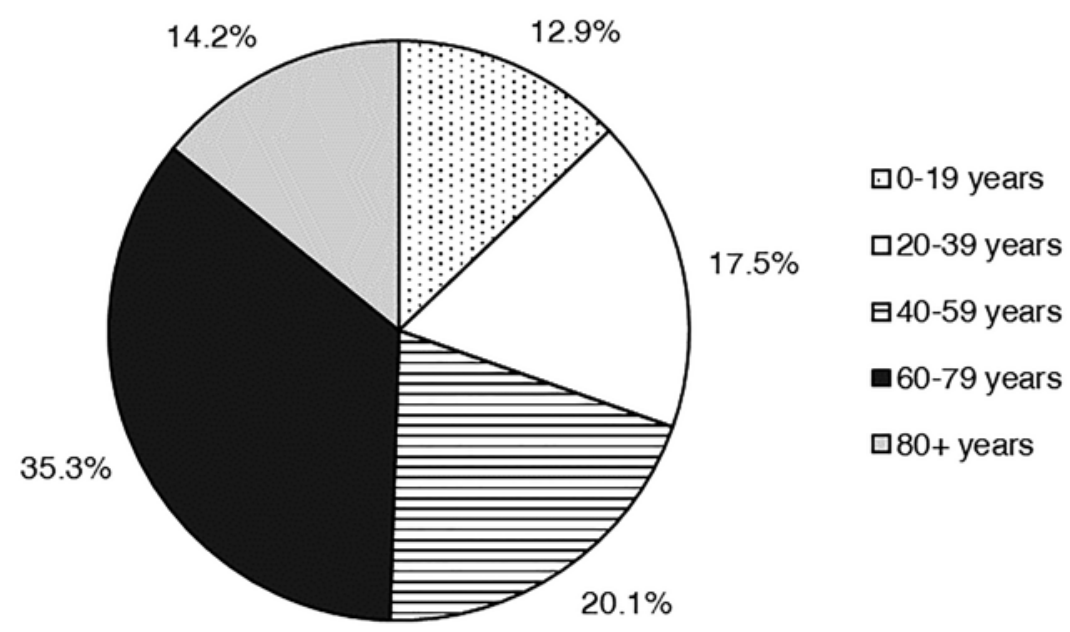

Figure 2. Distribution of Wisconsin Staphylococcus aureus surveillance isolates on the basis of patient age, 2018.

for Trends in Antimicrobial Resistance and Epidemiology (SWOTARE) program initiated an improved understanding of frank and emerging resistance by both determining percentage susceptibility data and calculating minimum inhibitory concentration (MIC) frequency distributions by Wisconsin region.

The purpose of this SWOTARE program investigation was to establish a Wisconsin S. aureus antibiogram and to elucidate potential geographic and demographic factors associated with antimicrobial resistance. Clinically-significant $S$. aureus isolates collected throughout the state were tested in a central laboratory using a standardized method. The presented antibiogram and associated ancillary data can serve as a baseline for future monitoring and surveillance of $S$. aureus antimicrobial resistance patterns throughout the state of Wisconsin.

\section{Materials and Methods}

\section{Region Demarcation}

The seven bioterrorism preparedness regions of the WCLN, as originally defined in 2001, served as the basis for geographic comparison within this study. Population density for each region was determined by querying 2010 United States Census population data for each county within a region (Figure 1), with that sum divided by the aggregate land area of counties located in that region (https://legis.wisconsin.gov/ lrb/blue-book/).

\section{Study Site Recruitment}

Three study sites were chosen from each region for provision of bacterial isolates. To prevent potential bias from larger population centers, two hospital microbiology laboratories from more rural areas and one from an area of higher population within the region were selected. Study locations included microbiology laboratories in Eau Claire, Spooner/ Ashland, and St. Croix Falls/Amery (Northwest region); Stevens Point, Marshfield, and Weston (Northcentral region); Green Bay (two locations) and Manitowoc (Northeast region); La Crosse, Platteville/Prairie du Chien, and Viroqua (Southwest region); Madison, Janesville/Monroe, and Fort Atkinson (Southcentral region); Appleton, Neenah, and Fond

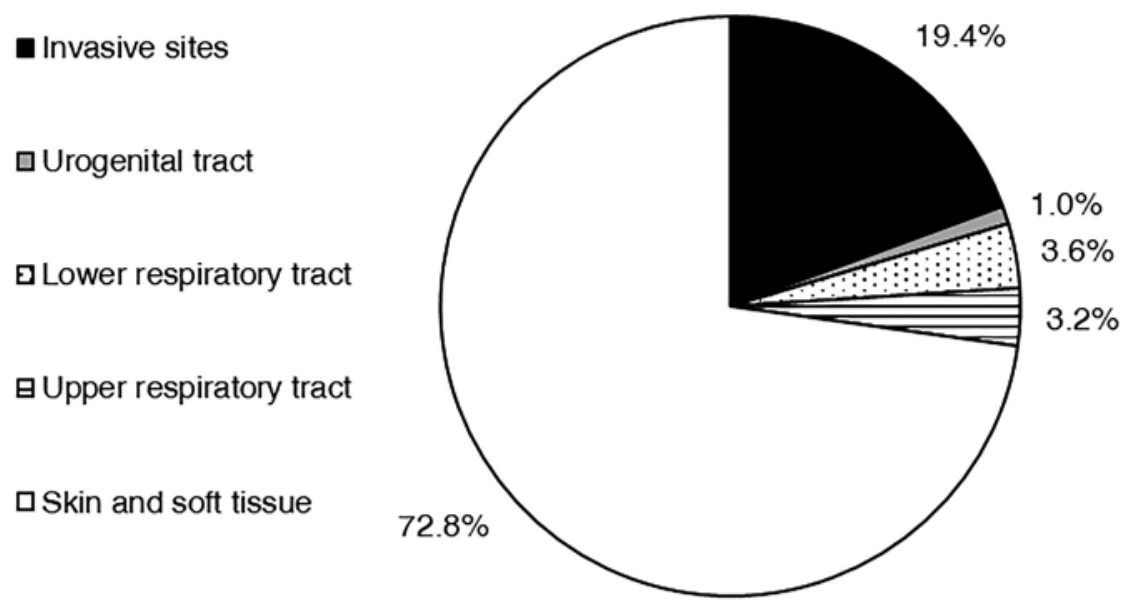

Figure 3. Distribution of Wisconsin Staphylococcus aureus surveillance isolates on the basis of specimen source, 2018. 


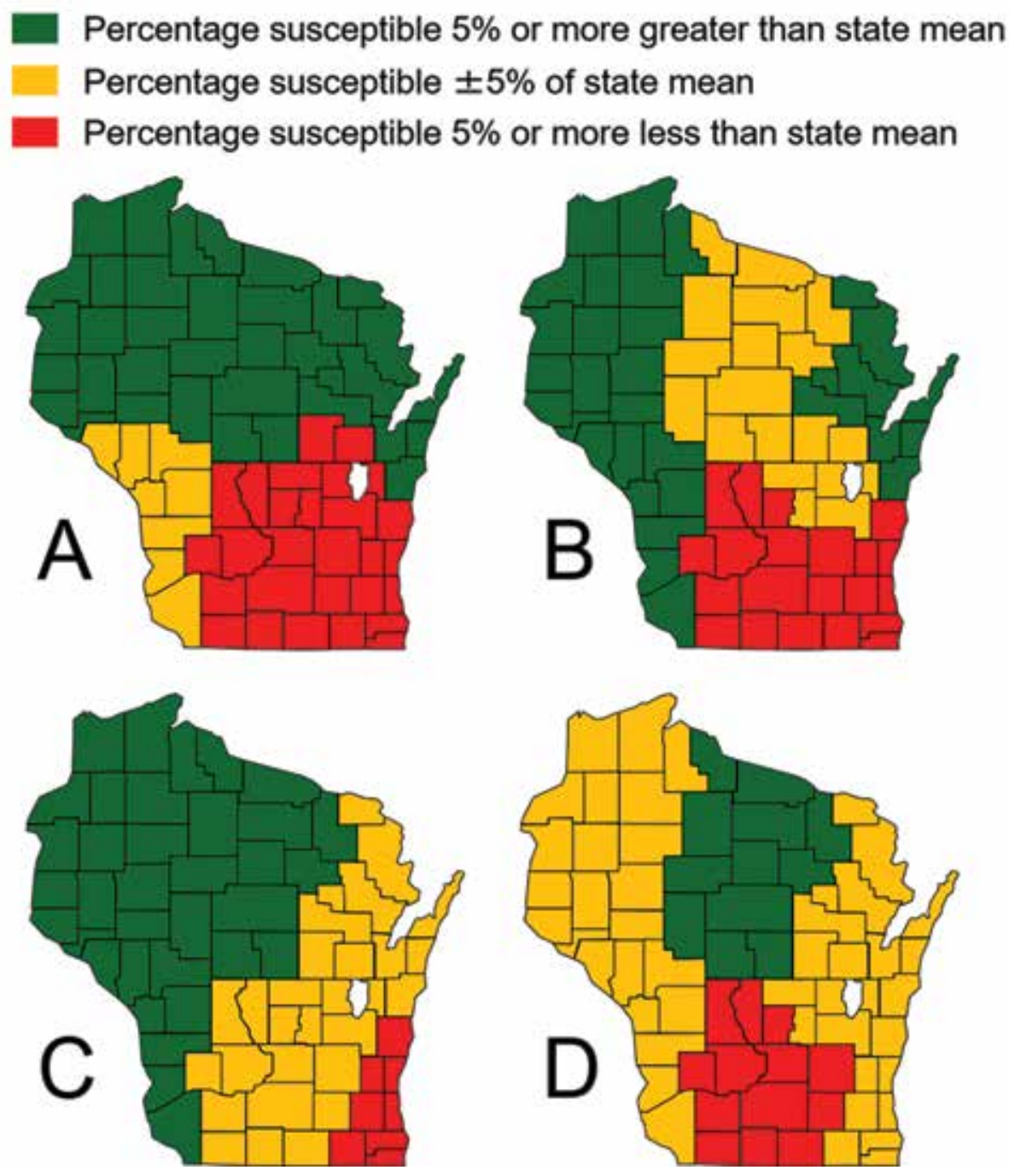

Figure 4. Wisconsin geographic differences in Staphylococcus aureus susceptibility to (A) cefoxitin, (B) levofloxacin, (C) erythromycin, and (D) clindamycin, 2018.

du Lac (Lake Winnebago region); and, Milwaukee, West Allis, and West Bend (Southeast region).

\section{Selection of Isolates}

Study sites were requested to forward 14-15 clinicallysignificant isolates of $S$. aureus to a centralized testing laboratory. Isolates were collected in consecutive (nonduplicate) fashion regardless of cefoxitin susceptibility result. This instruction attempted to prevent a bias toward MRSA within the collection. Any duplicate or nonviable isolates were excluded from the study. In addition, study sites were asked to provide limited demographic information related to age, gender, specimen source of isolate, and location of healthcare encounter. Access to protected health information for the purpose of surveillance was granted by the Marquette University Institutional Review Board. Because of the lack of direct involvement in the collection of specimens and because of the utilization of de-identified isolates from routine clinical care, the SWOTARE program was not considered to be actively engaged in human research subjects' research by the Marquette University Institutional Review Board.

\section{Test Performance}

Broth microdilution antimicrobial susceptibility testing was performed and interpreted using standards published by the Clinical and Laboratory Standards Institute (CLSI). ${ }^{20,21}$ Each isolate was tested against the antimicrobials listed in Table 1 in serial two-fold concentration dilutions that extended beyond CLSI breakpoints for susceptibility and resistance (when appropriate). Identification of MRSA phenotype occurred via cefoxitin susceptibility testing ${ }^{20,22}$ on the basis of increased induction of mecA activity. Isolates with a penicillin MIC of $\leq$ $0.12 \mu \mathrm{g} / \mathrm{mL}$ were subjected to nitrocefin-based $\beta$-lactamase testing, with follow-up zone edge testing for $\beta$-lactamasenegative isolates. $^{20}$ Isolates demonstrating a phenotype of erythromycin resistance (or intermediate resistance) and clindamycin susceptibility were subjected to inducible clindamycin resistance testing. ${ }^{20,23,24}$ Cefoxitin and vancomycin 
Table 1. Wisconsin Staphylococcus aureus antibiogram with delineation into methicillin-susceptible $S$. aureus (MSSA) and methicillin-resistant S. aureus (MRSA), 2018

\begin{tabular}{|c|c|c|c|c|}
\hline & & \multicolumn{3}{|c|}{ Percentage Susceptible } \\
\hline \multicolumn{2}{|l|}{ Antimicrobial Agent } & $\begin{array}{c}\text { MSSA } \\
(n=194)\end{array}$ & $\begin{array}{c}\text { MRSA } \\
(n=115)\end{array}$ & $\begin{array}{c}\text { Total } \\
(n=309)\end{array}$ \\
\hline \multirow{3}{*}{ Beta-lactams } & FOX & 100 & 0.0 & 62.8 \\
\hline & PEN & 17.0 & 0.0 & 11.0 \\
\hline & TAR & 100 & 99.1 & 99.7 \\
\hline Macrolide & ERY & 67.0 & 16.5 & 48.2 \\
\hline Lincosamide & CLI & 81.4 & 63.5 & 74.8 \\
\hline Aminoglycoside & GEN & 98.5 & 100 & 99.0 \\
\hline Fluoroquinolone & LEV & 88.7 & 49.6 & 74.1 \\
\hline \multirow{4}{*}{ Glyco/lipopeptides } & VAN & 100 & 100 & 100 \\
\hline & DAP & 100 & 99.1 & 99.7 \\
\hline & TEL & 100 & 99.1 & 99.7 \\
\hline & DAL & 100 & 100 & 100 \\
\hline \multirow{2}{*}{ Tetracyclines } & TET & 93.8 & 93.0 & 93.5 \\
\hline & DOX & 95.9 & 95.7 & 95.8 \\
\hline \multirow{2}{*}{ Others } & LZD & 100 & 100 & 100 \\
\hline & $\mathrm{T} / \mathrm{S}$ & 99.5 & 97.4 & 98.7 \\
\hline \multicolumn{5}{|c|}{$\begin{array}{l}\text { Abbreviations: FOX, cefoxitin; PEN, penicillin; TAR, ceftaroline; ERY, } \\
\text { erythromycin; CLI, clindamycin; GEN, gentamicin; LEV, levofloxacin; VAN, } \\
\text { vancomycin; DAP, daptomycin; TEL, telavancin; DAL, dalbavancin; TET, } \\
\text { tetracycline; DOX, doxycycline; LZD, linezolid; T/S, trimethoprim- } \\
\text { sulfamethoxazole }\end{array}$} \\
\hline
\end{tabular}

susceptibility testing results were determined following a full 24-hour incubation.

\section{Data Analysis}

Percentage susceptible, intermediate, and resistant values, as well as median MIC $\left(\mathrm{MIC}_{50}\right)$ and 90th percentile $\mathrm{MIC}\left(\mathrm{MIC}_{90}\right)$ determinations were made on a statewide or geographic basis. To characterize geographic variation, the statewide mean susceptibility percentage for a given organism/antimicrobial combination established a baseline value. An interval of 5\% on either side of that mean represented normal distribution. Region-specific values $\geq 5 \%$ less than the state mean indicated areas with increased resistance. Region-specific values $\geq 5 \%$ greater than the state mean indicated less resistance potential. The significance test of proportions determined if differences in susceptibility percentage among epidemiologic comparisons were significant. The alpha level was set at 0.05 before the investigations commenced, and all $P$ values are two-tailed.

\section{Results and Discussion}

Patient Demographics, Specimen Source, and Patient Location In 2018, 309 isolates of $S$. aureus were submitted to the surveillance program. Of this total, $155(50.2 \%)$ were isolated from males. The highest percentage of isolates was derived from patients between the ages of 60-79 years (35.3\%; Figure 2 ). Other age groups contributed between $12.9 \%$ and $20.1 \%$ of isolates. Most isolates emanated from inpatient care $(42.4 \%)$ or outpatient $(40.1 \%)$ encounters. The mean percentage of isolates emanating from inpatient collections as a function of individual study site was $39.9 \pm 5.82 \%$ (median $33.3 \%$ ). Only 54 isolates $(17.5 \%)$ resulted from emergency department visits. Of the 309 isolates, $72.8 \%$ came from a skin and soft tissue source (178 isolates from wounds, 26 from abscesses, 21 from tissue; Figure 3). Invasive sources comprised 19.4\% of the total isolates ( 50 from blood, 9 from aspirates, 1 from bone), and 3.6\% were derived from the lower respiratory tract ( 8 from sputum, 3 from semi-invasive respiratory procedures).

\section{S. aureus Antibiogram}

A $S$. aureus antibiogram for the state of Wisconsin is presented in Table 1. Across the state, gentamicin and trimethoprimsulfamethoxazole continue to maintain potency against both MRSA and methicillin-susceptible $S$. aureus (MSSA) in vitro, with $\geq 98.7 \%$ susceptibility $(95 \%$ confidence interval $[\mathrm{CI}] \geq$ $97.4,100)$. Tetracyclines demonstrated slightly less potency against MSSA and MRSA. Other Gram-positive agents such as vancomycin and linezolid demonstrated $100 \%$ in vitro susceptibility across Wisconsin. The vancomycin $\mathrm{MIC}_{90}$ value 
Table 2. $\mathrm{MIC}_{50}, \mathrm{MIC}_{90}$, and percentage susceptibility (\%S) of Wisconsin Staphylococcus aureus isolates to doxycycline, stratified by geographic region, 2018

\begin{tabular}{lcccccccc}
\hline & Northwest & Northcentral & Northeast & Southwest & Southcentral & Lake Winnebago & Southeast & Wisconsin \\
\hline $\mathbf{n}$ & 45 & 43 & 45 & 45 & 44 & 44 & 43 & 309 \\
MIC $_{50}$ & $\leq 0.5$ & $\leq 0.5$ & $\leq 0.5$ & $\leq 0.5$ & $\leq 0.5$ & $\leq 0.5$ & $\leq 0.5$ & $\leq 0.5$ \\
MIC $_{90}$ & $\leq 0.5$ & $\leq 0.5$ & $\leq 0.5$ & 4 & $\leq 0.5$ & $\leq 0.5$ & $\leq 0.5$ & $\leq 0.5$ \\
$\% S$ & 95.6 & 95.3 & 100 & 91.1 & 95.5 & 100 & 93 & 95.8 \\
\hline
\end{tabular}

for Wisconsin $S$. aureus isolates was $1 \mu \mathrm{g} / \mathrm{mL}$, which represented at least two 2 -fold dilutions below the CLSI intermediate interpretive range of $4-8 \mu \mathrm{g} / \mathrm{mL} .{ }^{20}$

With respect to doxycycline, tetracycline, and trimethoprimsulfamethoxazole, $0.2 \%$ to $2.1 \%$ differences in percentage susceptible values for MSSA and MRSA isolates were observed statewide. However, a distinct difference between MSSA and MRSA phenotypes was observed in terms of erythromycin, levofloxacin, and clindamycin susceptibility. Susceptibility percentages decreased by $50.5 \%$ (erythromycin), $39.1 \%$ (levofloxacin), and $17.9 \%$ (clindamycin) upon phenotypic classification as MRSA (Table 1). Similar increases in macrolide and fluoroquinolone resistance rates within a MRSA phenotype were reported from a recent ocular pathogen surveillance effort in the United States. ${ }^{25}$ In clinical practice, utilization of levofloxacin for staphylococcal infections is often limited to specific entities and would be used in combination with rifampin. ${ }^{26}$

Geographic Variation in Wisconsin S. aureus Resistance

Outside of penicillin, the only agents $S$. aureus isolates throughout Wisconsin demonstrate appreciable in vitro resistance to include clindamycin $(74.8 \%$ susceptibility; CI 70.0, 79.6), levofloxacin (74.1\% susceptibility; CI 69.2, 79.0), and erythromycin (48.2\% susceptibility; CI 42.6, 53.8) (Table 1). The identification of clindamycin-resistant isolates was augmented by a positive inducible clindamycin resistance result in $31.4 \%$ of 118 statewide isolates eligible for testing. Of Wisconsin isolates tested, 37.2\% (CI 31.8, 42.6) were phenotypically classified as MRSA, with the highest rates in the Lake Winnebago $(50.0 \%$; CI $35.2,64.8)$, Southeast (46.5\%; CI 31.6, 61.4), and Southcentral (45.5\%; CI 30.8, 60.2 ) regions (Figure $4 \mathrm{~A}$ ). Remaining agents exhibited strong in vitro efficacy in the context of both MSSA and MRSA.

Emerging doxycycline resistance may be evident among $S$. aureus isolates in Southwest Wisconsin. While the percentage of isolates susceptible to this agent in this region exhibited only a $4.7 \%$ deviation from the state mean (Table 2), a distinct difference in $\mathrm{MIC}_{90}$ value was observed. The Southwest region $\mathrm{MIC}_{90}$ value of $4 \mu \mathrm{g} / \mathrm{mL}$ was at least three 2 -fold dilution values higher than the state $\mathrm{MIC}_{90}$ value. This is important, as a doxycycline MIC of $4 \mu \mathrm{g} / \mathrm{mL}$ is at the upper limit of the CLSI susceptible interpretive category. ${ }^{20}$ Analysis of MIC frequency distributions (in addition to susceptibility percentages) can be helpful in predicting future trends in resistance patterns, particularly when these MIC values still lie within a CLSI susceptible interpretive category.

Past data from the United States $^{27}$ introduced the incidence of doxycycline resistance in MRSA phenotypes that exhibited decreased susceptibility to oxacillin, erythromycin, and levofloxacin. Within this phenotype, which represented $31 \%$ of MRSA isolates surveyed, $4.2 \%$ of isolates were resistant to doxycycline. Jones, et $\mathrm{al}^{28}$ utilized the doxycycline susceptible breakpoint of $4 \mu \mathrm{g} / \mathrm{mL}$ to report $96.2 \%$ and $99.2 \%$ susceptibility rates for worldwide MRSA and MSSA isolates, respectively. These values were 5\% greater than corresponding tetracycline susceptibility rates. MIC frequency distribution analysis of Wisconsin data regarding another alternative $S$. aureus therapeutic agent, trimethoprim-sulfamethoxazole, did not reveal potential emerging trends of resistance (data not illustrated). Additional investigation into this doxycycline/S. aureus paradigm from the Southwest region may be warranted to further elucidate this potential emerging resistance profile.

In addition to an increased frequency of MRSA, S. aureus isolates derived from the Southeast, Southcentral, and Lake Winnebago regions exhibited increased resistance to levofloxacin (Figure 4B), erythromycin (Figure 4C), and clindamycin (Figure 4D) when compared to other Wisconsin regions. In these regions, increased surveillance efforts through the SWOTARE program and concomitant adjustments to antimicrobial stewardship programs have the potential to impact future resistance profiles. Investigations are in progress to assess provider prescribing patterns within these regions of Wisconsin and to determine any correlation with known resistance patterns.

Hicks, et $\mathrm{al}^{29}$ reported significant antibiotic prescription burden within outpatient settings in the United States, with over 260 million courses being prescribed by clinicians in 2011. Agents within seven antimicrobial classes (including penicillins, macrolides, fluoroquinolones, and tetracyclines) accounted for $94 \%$ of total outpatient prescriptions. Antimicrobial resistance surveillance is particularly necessary in the Midwest region of the United States, as an average of 897 outpatient prescriptions per 1000 persons was issued in this 12 -state region in 2011, second only to the southern United States (931 prescriptions per 1000 persons). ${ }^{29}$ Analyzing local patterns of resistance by geographic region, patient population, and practitioner specialty could provide insight into antimicrobial resistance beyond that relative to inpatient 
Table 3. $\mathrm{MIC}_{50}, \mathrm{MIC}_{90}$, and percent susceptibility (\%S) of Wisconsin Staphylococcus aureus isolates to telavancin (TEL), dalbavancin (DAL), and ceftaroline (TAR), stratified by geographic region, 2018

\begin{tabular}{|c|c|c|c|c|c|c|c|c|}
\hline TEL & Northwest & Northcentral & Northeast & Southwest & Southcentral & Lake Winnebago & Southeast & Wisconsin \\
\hline $\mathrm{n}$ & 45 & 43 & 45 & 45 & 44 & 44 & 43 & 309 \\
\hline $\mathrm{MIC}_{50}$ & 0.06 & 0.12 & 0.06 & 0.06 & 0.06 & 0.06 & 0.12 & 0.06 \\
\hline $\mathrm{MIC}_{90}$ & 0.12 & 0.12 & 0.12 & 0.06 & 0.12 & 0.12 & 0.12 & 0.12 \\
\hline$\% \mathrm{~S}$ & 100 & 100 & 100 & 100 & 97.7 & 100 & 100 & 99.7 \\
\hline DAL & Northwest & Northcentral & Northeast & Southwest & Southcentral & Lake Winnebago & Southeast & Wisconsin \\
\hline $\mathrm{n}$ & 45 & 43 & 45 & 45 & 44 & 44 & 43 & 309 \\
\hline $\mathrm{MIC}_{50}$ & 0.06 & 0.06 & 0.06 & 0.06 & 0.06 & 0.06 & 0.06 & 0.06 \\
\hline $\mathrm{MIC}_{90}$ & 0.06 & 0.06 & 0.06 & 0.06 & 0.06 & 0.06 & 0.06 & 0.06 \\
\hline$\% S$ & 100 & 100 & 100 & 100 & 100 & 100 & 100 & 100 \\
\hline TAR & Northwest & Northcentral & Northeast & Southwest & Southcentral & Lake Winnebago & Southeast & Wisconsin \\
\hline$n$ & 45 & 43 & 45 & 45 & 44 & 44 & 43 & 309 \\
\hline $\mathrm{MIC}_{50}$ & 0.25 & $\leq 0.12$ & 0.25 & 0.25 & 0.25 & 0.25 & 0.25 & 0.25 \\
\hline $\mathrm{MIC}_{90}$ & 0.5 & 0.25 & 0.25 & 0.5 & 0.5 & 0.5 & 0.5 & 0.5 \\
\hline$\% S$ & 100 & 100 & 100 & 100 & 97.7 & 100 & 100 & 99.7 \\
\hline
\end{tabular}

populations or healthcare-associated infections. The SWOTARE program, with its inherent design allowing for participation by rural healthcare facilities, can assist in future analyses.

In this study, three agents with recently established CLSI guidelines ${ }^{20,30,31}$ were tested against each $S$. aureus isolate to contribute to the baseline antibiogram (Table 3). Telavancin does not currently possess a resistant interpretive breakpoint; ${ }^{20}$ however, one isolate was found to be non-susceptible to this agent (surgical tissue isolate from Southcentral region, MIC of $0.25 \mu \mathrm{g} / \mathrm{mL}$ ). $\mathrm{MIC}_{50}$ and $\mathrm{MIC}_{90}$ values were consistent throughout Wisconsin for dalbavancin (both $0.06 \mu \mathrm{g} / \mathrm{mL}$ ). $S$. aureus susceptibility to telavancin and ceftaroline demonstrated some variation with respect to MIC values; however, none exceeded the CLSI susceptible breakpoint. Telavancin $\mathrm{MIC}_{50}$ and $\mathrm{MIC}_{90}$ values were calculated at either $0.06 \mu \mathrm{g} / \mathrm{mL}$ or $0.12 \mu \mathrm{g} / \mathrm{mL}$ on a geographic basis. Ceftaroline $\mathrm{MIC}_{50}$ and $\mathrm{MIC}_{90}$ values ranged from $\leq 0.12 \mu \mathrm{g} / \mathrm{mL}$ to $0.5 \mu \mathrm{g} /$ $\mathrm{mL}$ across the state; $>95 \%$ of all isolates tested susceptible to these three agents in each region. One daptomycin nonsusceptible isolate (MIC of $2 \mu \mathrm{g} / \mathrm{mL}$ ) was identified from the Southwest region of the state.

Demographic Variation S. aureus Resistance in Wisconsin In addition to geographic variability associated with MRSA in Wisconsin, we also observed differences as a function of patient age. Patients aged 20-39 years generated the highest proportion of $S$. aureus isolates with a MRSA phenotype (57.4\%; Table 4), while MRSA rates in patients aged 0-19 years, $40-59$ years, and $60-79$ years approximated $30 \%(P \leq$ $0.03)$. These findings extend those derived from a United States tertiary care center in which MRSA was detected more frequently in patients under the age of 24 when compared to other age groups. ${ }^{32}$

These authors hypothesized that increased risk of MRSA among younger individuals may be related to increased participation in what was termed risky activity (such as team sports). One past study ${ }^{33}$ reported the median age of community-acquired MRSA infection to be significantly less than that in cases of healthcare-associated MRSA infection. Our findings contrast a European study that reported an increased proportion of MRSA in elderly patients when compared to younger patients. ${ }^{34}$ Further investigation may be warranted in subsequent SWOTARE collections to elucidate a role for patient age in terms of risk for MRSA infection in Wisconsin.

Other differences were noted with levofloxacin and clindamycin. An increased proportion of levofloxacinresistant $S$. aureus from patients aged 80 or older was observed compared to patients aged $0-19$ or $40-59$ years $(P \leq$ 0.046; Table 4). This elderly population also exhibited an increased percentage of $S$. aureus resistant to clindamycin (36.3\%) when compared to $20-39$ year olds $(16.7 \%, P=$ $0.026)$. Moreover, when compared to the 40-59 year-old population, resistance rates trended higher in the $80+$ years group $(P=0.08)$. These data extend findings from David, et $\mathrm{al}^{35}$ who demonstrated increased $S$. aureus resistance to clindamycin in elderly patients when compared to pediatric patients. Moreover, findings from pediatric patients treated in United States military facilities from 2005-2014 documented annual clindamycin resistance rates between $9.3 \%$ and $14.4 \%{ }^{36}$ However, recent pediatric data from the Baltimore, Maryland area collected over a 12-year interval reported an 
Table 4. Comparative Wisconsin Staphylococcus aureus resistance to cefoxitin (FOX), levofloxacin (LEV), erythromycin (ERY), clindamycin (CLI), doxycycline (DOX), and trimethoprim-sulfamethoxazole (T/S), stratified by age group, 2018

\begin{tabular}{|c|c|c|c|c|c|c|}
\hline \multirow[b]{2}{*}{ Age group } & \multicolumn{6}{|c|}{ Percentage Resistant to Antimicrobial Agents } \\
\hline & FOX & LEV & ERY & CLI & DOX $^{a}$ & T/S \\
\hline $0-19$ & 35.0 & 15.0 & 55.0 & 20.0 & 2.5 & 0.0 \\
\hline 20-39 & $57.4^{b}$ & 24.1 & 51.9 & 16.7 & 1.9 & 1.9 \\
\hline $40-59$ & 30.7 & 21.0 & 43.6 & 21.0 & 4.8 & 1.6 \\
\hline $60-79$ & 30.3 & 28.4 & 42.7 & 28.4 & 5.5 & 1.8 \\
\hline $80+$ & 40.9 & $38.6^{c}$ & 56.8 & $36.3^{d}$ & 4.6 & 0.0 \\
\hline $\begin{array}{l}\text { aPercentages reflec } \\
\text { were not observed. } \\
{ }^{\mathrm{b} P} \leq 0.03 \text { vs. } 0-19 y \\
{ }^{\mathrm{c}} \mathrm{P} \leq 0.046 \text { vs } 40-59 \\
{ }^{\mathrm{d}} \mathrm{P}=0.026 \text { vs. } 20-3\end{array}$ & $\begin{array}{l}\text { /cycline } \\
40-59 \text { ye } \\
\text { s, } 0-19 y \\
\text { ss }\end{array}$ & mediate & ance (M & $(\mathrm{mL})$; iso & with MIC & $\mu \mathrm{g} / \mathrm{mL}$ \\
\hline
\end{tabular}

increase in clindamycin resistance rate from $21 \%$ to $38 \%$ in MRSA clinical isolates and from $5 \%$ to $40 \%$ in MSSA isolates. ${ }^{37}$ Sutter et al..$^{36}$ also noted significant decreases in MSSA susceptibility to clindamycin over time when compared to pediatric MRSA isolates. As such, revisiting these demographic studies in subsequent Wisconsin surveillance efforts may be warranted. In the context of additional alternative staphylococcal regimens, trimethoprimsulfamethoxazole resistance rates and distributions of doxycycline intermediate MIC values did not demonstrate variation across age groupings $(P \geq 0.36$ and $P \geq 0.28$, respectively; Table 4).

No significant differences were noted with respect to cefoxitin, levofloxacin, erythromycin, and clindamycin resistance rates in isolates of $S$. aureus when stratified by inpatient, outpatient, or emergency department encounter. Resistance rates ranged from $32.8 \%$ to $41.0 \%$ between the three facility groupings for cefoxitin $(P \geq 0.18), 21.4 \%$ to $30.3 \%$ for levofloxacin $(P \geq$ $0.10), 46.7 \%$ to $50.0 \%$ for erythromycin $(P \geq 0.68)$, and $17.9 \%$ to $27.9 \%$ for clindamycin $(P \geq 0.15)$. These data further suggest that potential outpatient bias factored little into observations made in the study.

\section{Limitations}

Limitations to the desired two rural laboratory/one largerpopulation center laboratory approach to study site recruitment included regions with fewer hospital microbiology laboratories and regions with increased population density. The Southeast, Northeast, and Lake Winnebago regions were represented by fewer than two rural laboratories. The Northeast region of Wisconsin has experienced a movement toward hospital microbiology laboratory consolidation over the past decade. With respect to the Lake Winnebago and Southeast regions, population density figures of 151.4 and 670.8 inhabitants/ square mile were calculated, respectively. In contrast, three of the Wisconsin regions exhibited population density data of $<$ 50 inhabitants/square mile. As further evidence of measures taken to ensure a representative sampling that was not biased toward heavily urban centers during this 2018 surveillance effort, $38 \%$ of participating hospital microbiology laboratories were derived from municipalities with populations $<15,000$ (per 2010 United States census data), with an aggregate 58\% of participants derived from municipalities with populations $<$ 35,000 .

A second limitation is related to potential $S$. aureus clonality contributing to noted geographic variation. We were unable to investigate this possibility during this initial surveillance effort. As mentioned previously, approximately one-half of isolates were derived from hospital laboratories in rural areas of the state; these laboratories do not have the capacity to perform molecular epidemiologic studies. In addition, the limited demographic information requested of the study sites did not inquire about potential mini-outbreak status of isolates. Moreover, limited demographic information (as allowed by Institutional Review Board) did not allow for provision of patient identifiers, as such, retrospective investigation of potential mini-outbreak status could not be facilitated.

\section{Conclusion}

While limited to an extent by numbers of isolates collected in the initial year of SWOTARE $S$. aureus surveillance, presented data identified both geographic and demographic-based differences in antimicrobial resistance among Wisconsin $S$. aureus isolates. By carefully analyzing regional data, trends can be realized that are not apparent at a national level. In addition, regions of the state that warrant increased vigilance and intervention can be identified in efforts to mitigate antimicrobial resistance. Continued future surveillance efforts may reveal additional trends and contribute to stewardship and intervention opportunities at the local level.

\section{Acknowledgments}

The authors are grateful to the following individuals for collection of isolates throughout 2018: 
Sonja Alt, Monroe

Jorn Bansberg, Viroqua

Sherry Barta, Green Bay

Eric Beck, PhD, West Allis

Tim Block, West Bend

Becky Brooks, Stevens Point

Tracy Felland, Janesville

Thomas Fritsche, MD, PhD, Marshfield

Ben Kaetterhenry, Appleton

Debra Kieler, Platteville

Timothy Kramme, Milwaukee

Joshua Kropp, Weston

Kathy Lang, Ashland

Debbie Maedke, Manitowoc

Brooke Olson, Marshfield

Mattie Pitts, Spooner

Ray Podzorski, PhD, Madison

Lori Reed, Amery

Andrea Roder, Green Bay

Karen Siebers, Neenah

Brian Simmons, Prairie du Chien

Mary A. Smith, St. Croix Falls

Frances Spray-Larson, PhD, Fort Atkinson

Janelle Stearns, Eau Claire

Sarah Stoner, La Crosse

Ellen Wirtz, Fond du Lac

\section{References}

1. World Health Organization. Antibiotic Resistance. 2018. Available at: www. who.int/news-room/fact-sheets/detail/ antibiotic-resistance. Accessed April 18, 2019.

2. Sievert DM, Ricks P, Edwards JR, et al. Antimicrobial-resistant pathogens associated with healthcare-associated infections: summary of data reported to the National Healthcare Safety Network at the Centers for Disease Control and Prevention, 2009-2010. Infect Control Hosp Epidemiol. 2013;34(1):1-14.

3. Magill SS, O'Leary E, Janelle SJ, et al. Changes in prevalence of health care-associated infections in U.S. hospitals. N Engl J Med. 2018;379(18):1732-1744.

4. Thomson KS. The immaculate carbapenemase study. J Clin Microbiol. 2017;55(6):1608 1611.

5. Lamoth F, Kontoyiannis DP. The Candida auris alert: facts and perspectives. J Infect Dis. 2018;217(4):516-520.

6. Day MJ, Spiteri G, Jacobsson S, et al. Stably high azithromycin resistance and decreasing ceftriaxone susceptibility in Neisseria gonorrhoeae in 25 European countries, 2016. BMC Infect Dis. 2018;18(1):609.

7. Roberts RR, Hota B, Ahmad I, et al. Hospital and societal costs of antimicrobial-resistant infections in a Chicago teaching hospital: implications for antibiotic stewardship. Clin Infect Dis. 2009;49(8):1175-1184.

8. World Health Organization. WHO publishes list of bacteria for which new antibiotics are urgently needed. 2017. Available at: www.who.int/news-room/detail/27-02-2017-whopublishes-list-of-bacteria-for-which-new-antibiotics-areurgently-needed. Accessed March 20, 2019.

9. Munson E. Biographical feature: Clyde Thornsberry, Ph.D. J Clin Microbiol. 2016;54(2):250 253.

10. Lowy FD. Antimicrobial resistance: the example of Staphylococcus aureus. J Clin Invest. 2003;111(9):12651273.
11. World Health Organization. Antimicrobial resistance: global report on surveillance. 2014. Available at: https://www.who. int/drugresistance/documents/surveillancereport/en/. Accessed April 25, 2019.

12. U.S. Department of Health and Human Services. Centers for Disease Control and Prevention. Antibiotic resistance threats in the United States. 2013. Available at: http://www.cdc.gov/ drugresistance/threat-report-2013/pdf/ar-threats-2013-508. pdf. Accessed April 18, 2019.

13. Diekema DJ, Pfaller MA, Shortridge D, Zervos M, Jones RN. Twenty-year trends in antimicrobial susceptibilities among Staphylococcus aureus from the SENTRY antimicrobial surveillance program. Open Forum Infect Dis. 2019;6(Suppl 1):S47-S53

14. Sader HS, Mendes RE, Streit JM, Flamm RK. Antimicrobial susceptibility trends among Staphylococcus aureus isolates from U.S. hospitals: results from 7 years of the ceftaroline (AWARE) surveillance program, 2010-2016. Antimicrob Agents Chemother. 2017;61(9):e01043-17.

15. Landrum ML, Neumann C, Cook C, et al. Epidemiology of Staphylococcus aureus blood and skin and soft tissue infections in the US military health system, 2005-2010. JAMA. 2012;308(1):50-59.

16. Munson E, Zeman H, Hueppchen E. Surveillance of Wisconsin Organisms for Trends in Antimicrobial Resistance and Epidemiology (SWOTARE): epidemiologic correlates for 2016 surveillance isolates. Gundersen Medical Journal. 2017;10(1):41-48.

17. Munson E, Hueppchen E, Zeman H. Surveillance of Wisconsin Organisms for Trends in Antimicrobial Resistance and Epidemiology (SWOTARE): introduction to the program and summary of 2016 geographic variation. WMJ. 2018;117(3):116-121.

18. Zeman H, Martin R, Munson E, Schulte R. Surveillance of Wisconsin Organisms for Trends in Antimicrobial Resistance and Epidemiology (SWOTARE): summary of 2017 findings with focus on changing resistance patterns in selected antimicrobial classes. Gundersen Medical Journal. In press.

19. Munson E, Block TK, Bowles EJ, et al. Surveillance of Wisconsin antibacterial susceptibility patterns. WMJ. 2016;115(1):29-36.

20. Clinical and Laboratory Standards Institute (CLSI). Performance standards for antimicrobial susceptibility testing, M100. 28th informational supplement. Wayne, PA: CLSI; 2018.

21. Clinical and Laboratory Standards Institute (CLSI). Methods for dilution antimicrobial susceptibility tests for bacteria that grow aerobically, M07. 10th ed. Wayne, PA: CLSI; 2015.

22. McKinney TK, Sharma VK, Craig WA, Archer GL. Transcription of the gene mediating methicillin resistance in Staphylococcus aureus (mecA) is corepressed but not coinduced by cognate mecA and beta-lactamase regulators. $\mathrm{J}$ Bacteriol. 2001;183(23):6862-6868.

23. Prabhu K, Rao S, Rao V. Inducible clindamycin resistance in Staphylococcus aureus isolated from clinical samples. J Lab Physicians. 2011;3(1):25-27.

24. Fiebelkorn KR, Crawford SA, McElmeel ML, Jorgensen JH. Practical disk diffusion method for detection of inducible clindamycin resistance in Staphylococcus aureus and coagulase-negative staphylococci. J Clin Microbiol. 2003;41(10):4740-4744.

25. Asbell PA, Sanfilippo CM, Pillar CM, DeCory HH, Sahm DF, Morris TW. Antibiotic resistance among ocular pathogens in the United States: five-year results from the Antibiotic Resistance Monitoring in Ocular Microorganisms (ARMOR) surveillance study. JAMA Ophthalmol. 2015;133(12):14451454. 
26. Liu C, Bayer A, Cosgrove SE, et al. Clinical practice guidelines by the infectious diseases society of america for the treatment of methicillin-resistant Staphylococcus aureus infections in adults and children. Clin Infect Dis. 2011;52(3):e18-e55.

27. McDougal LK, Fosheim GE, Nicholson A, et al. Emergence of resistance among USA300 methicillin-resistant Staphylococcus aureus isolates causing invasive disease in the United States. Antimicrob Agents Chemother. 2010;54(9):3804-3811.

28. Jones RN, Stilwell MG, Wilson ML, Mendes RE. Contemporary tetracycline susceptibility testing: doxycycline MIC methods and interpretive criteria (CLSI and EUCAST) performance when testing Gram-positive pathogens. Diagn Microbiol Infect Dis. 2013;76(1):69-72.

29. Hicks LA, Bartoces MG, Roberts RM, et al. US outpatient antibiotic prescribing variation according to geography, patient population, and provider specialty in 2011. Clin Infect Dis. 2015;60(9):1308-1316.

30. Clinical and Laboratory Standards Institute (CLSI). Performance standards for antimicrobial susceptibility testing, M100. 23rd informational supplement. Wayne, PA: CLSI; 2013.

31. Clinical and Laboratory Standards Institute (CLSI).

Performance standards for antimicrobial susceptibility testing, M100. 26th informational supplement. Wayne, PA: CLSI; 2016.

32. Jacobus CH, Lindsell CJ, Leach SD, Fermann GJ, Kressel AB, Rue LE. Prevalence and demographics of methicillin resistant Staphylococcus aureus in culturable skin and soft tissue infections in an urban emergency department. BMC Emerg Med. 2007;7(1):19.

33. Naimi TS, LeDell KH, Como-Sabetti K, et al. Comparison of community- and health care-associated methicillin-resistant Staphylococcus aureus infection. JAMA. 2003;290(22):29762984.

34. Pomorska-Wesołowska M, Różańska A, Natkaniec J, et al. Longevity and gender as the risk factors of methicillinresistant Staphylococcus aureus infections in southern Poland. BMC Geriatr. 2017;17(1):51.

35. David MZ, Crawford SE, Boyle-Vavra S, Hostetler MA, Kim DC, Daum RS. Contrasting pediatric and adult methicillinresistant Staphylococcus aureus isolates. Emerg Infect Dis. 2006;12(4):631-637.

36. Sutter DE, Milburn E, Chukwuma U, Dzialowy N, Maranich AM, Hospenthal DR. Changing susceptibility of Staphylococcus aureus in a US pediatric population. Pediatrics. 2016;137(4):e20153099.

37. Khamash DF, Voskertchian A, Tamma PD, Akinboyo IC, Carroll KC, Milstone AM. Increasing clindamycin and trimethoprim-sulfamethoxazole resistance in pediatric Staphylococcus aureus infections. J Pediatric Infect Dis Soc. 2019;8(4):351-353.

\section{Author Affiliations}

Rebecca H. Schulte, BS* and Erik Munson, PhD*†

*College of Health Sciences, Marquette University, Milwaukee, Wisconsin USA

†Wisconsin Clinical Laboratory Network Technical Advisory

Group, Madison, Wisconsin USA 